\title{
Is "Strict" Conventional Therapy Enough for the Treatment of Coronary Artery Disease?
}

\author{
Yasuhiko Sakata, MD, PhD
}

D espite increased implementation of evidence-based therapy in recent years, there still remains a significant cardiovascular risk for patients with coronary artery disease (CAD). For example, the Japanese Coronary Artery Disease (JCAD) Study Investigators reported that the incident rate of cardiovascular events in CAD patients was approximately 62.8 per 1,000 patient-years in Japan, a much higher incident rate in comparison with that for the general population. ${ }^{1}$ Therefore, in the clinical setting, physicians have been obliged to at least consider intensive treatment for CAD patients, although there are no convincing goals of the intensive management of coronary risk factors, especially for blood pressure (BP) management.

\section{Article p 2062}

In this context, the results of the JCADII study are of much clinical interest because this is the first study to evaluate the efficacy of intensive lowering of both BP and low-densitylipoprotein cholesterol (LDL-C) on secondary prevention for CAD. ${ }^{2}$ In that study, a total of 498 Japanese CAD patients with hypertension and hypercholesterolemia were randomly assigned to conventional therapy (CT) or intensive therapy (IT), where CT aimed to reduce BP to $<140 / 90 \mathrm{mmHg}$ and LDL-C to $<100 \mathrm{mg} / \mathrm{dl}$, and IT aimed for $<120 / 80 \mathrm{mmHg}$ and $<80 \mathrm{mg} / \mathrm{dl}$, respectively. Contrary to prior expectation, however, intensive lowering of both BP and LDL-C provided no beneficial effect in terms of reducing cardiovascular risk, even with a tendency for worse outcomes in the CT group: the primary composite endpoint of all deaths and other vascular diseases occurred in 18 (7.1\%) patients in the CT group, whereas it was in $26(10.7 \%)$ in the IT group (hazard ratio $1.53,95 \%$ confidence interval $0.84-2.80, \mathrm{P}=0.164$ ).

Although further studies are necessary to confirm the results, this observation is highly suggestive that further IT is not necessarily needed in CAD patients when CT is strictly provided. As the authors discuss in their paper, cardiovascular risk was well reduced in the study population (3\%/year), which is extremely low compared with that of previous reports that investigated the effects of intensive management of coronary risk factors in patients with CAD. ${ }^{3-10}$ Notably, along with its satisfactory reduction of $\mathrm{BP}(126.8 / 70.8 \mathrm{mmHg})$ and LDL-C $(92.1 \mathrm{mg} / \mathrm{dl})$, the incidence of the primary composite endpoint in the CT group was only $2.2 \% / y e a r$. That is, the adverse effects of intensive lowering of BP, LDL-C, or both, might have outweighed their benefits in the IT group in the
JCADII study. In other words, the study may suggest that further intensive management should be considered based on the personal risk: intensive management might be necessary only for high-risk patients, in whom the benefits are supposed to outweigh the risk.

The JCADII study provides other important perspectives. First, the results suggest that diastolic BP (DBP) of $70 \mathrm{mmHg}$ could be the lower end in the management of CAD patients in Japan. Second, it may be the time to re-consider the method of LDL-C lowering.

\section{The J-Curve Phenomenon}

Because the coronary vasculature receives blood flow mostly during diastole, an excessive decrease in DBP may significantly hamper coronary perfusion, leaving the practicing physician with the dilemma that lowering BP to the level that prevents stroke or renal disease might precipitate adverse coronary ischemic events (J-curve phenomenon). Although the topic of the J-curve relationship between BP and the occurrence of ischemic coronary events has been controversial, now there seems a consensus that there is an inverse relationship at least between DBP and adverse cardiac ischemic events in patients with CAD. ${ }^{3,4}$ However, because no large scale randomized clinical trials were primarily designed to compare different BP level targets in CAD patients, there is no convincing goal for the most appropriate BP treatment in patients with CAD $;{ }^{4}$ US guidelines recommend a target $<130 / 80 \mathrm{mmHg}$, whereas European guidelines do not consistently support such an aggressive target, for example.

Recently, a secondary analysis of the INternational VErapamil-trandolapril STudy (INVEST) revealed that the risk for the primary outcome, all-cause death, and myocardial infarction, progressively increased with low DBP, with a nadir of $84 \mathrm{mmHg}$ (the nadir for systolic BP was $119 \mathrm{mmHg}$ ) in 22,576 patients with CAD: the primary outcome doubled when DBP was $<70 \mathrm{mmHg}$ and quadrupled when it was $<60 \mathrm{mmHg}$, while the risk of stroke did not increase with low DBP (Figure). ${ }^{5}$ In the JCADII trial, DBP was lowered to $67.9 \mathrm{mmHg}$ for the IT group, but was $70.8 \mathrm{mmHg}$ for the CT group. Therefore, intensive treatment might have likely increased the number of patients whose mean DBP was finally decreased to $<70 \mathrm{mmHg}$, causing the adverse events in the JCADII study.

Further LDL-C Lowering in the Evidenced-Based Medicine Era It should be noted that, compared with the previous randomized trials of intensive vs. standard-dose statin therapy, ${ }^{6-9}$

The opinions expressed in this article are not necessarily those of the editors or of the Japanese Circulation Society.

Received August 5, 2011; accepted August 5, 2011; released online August 11, 2011

Department of Cardiovascular Medicine, Osaka University Graduate School of Medicine, Suita, Japan

Mailing address: Yasuhiko Sakata, MD, PhD, Department of Cardiovascular Medicine, Osaka University Graduate School of Medicine,

2-2 Yamadaoka, Suita 565-0871, Japan. E-mail: sakatayk@cardiology.med.osaka-u.ac.jp

ISSN-1346-9843 doi:10.1253/circj.CJ-11-0858

All rights are reserved to the Japanese Circulation Society. For permissions, please e-mail: cj@j-circ.or.jp 


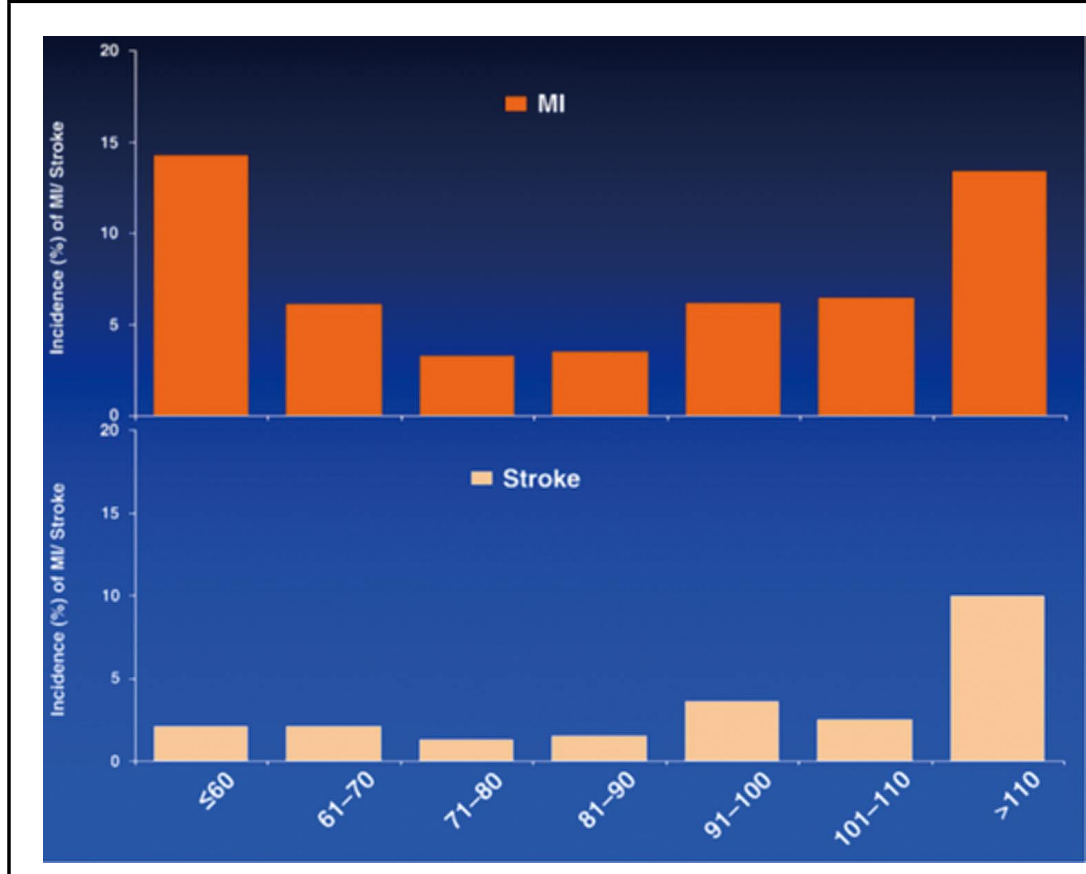

Figure. Incidence of myocardial infarction (MI) and stroke stratified by diastolic blood pressure (DBP) in the INVEST Study. ${ }^{5}$ Incidence of $\mathrm{Ml}$ doubled when DBP was $<70 \mathrm{mmHg}$ and quadrupled when it was $<60 \mathrm{mmHg}$ (Upper), while the risk of stroke did not (Lower). (Adopted from Messerli FH \& Panjrath GS. ${ }^{3}$ )

the achieved LDL-C levels after randomization in the JCADII study were lower in the CT group $(92.1 \mathrm{mg} / \mathrm{dl})$ and higher in the IT group $(79.6 \mathrm{mg} / \mathrm{dl})$ : estimated means of achieved LDL-C levels in the previous trials ${ }^{6-9}$ were $101 \mathrm{mg} / \mathrm{dl}$ and $75 \mathrm{mg} / \mathrm{dl}$ for the standard and intensive treatment groups, respectively. ${ }^{10}$ Accordingly, an excellent achievement of LDL-C lowering in the CT group, and as a result, a relatively small reduction of LDL-C levels might have minimized the impact of lowering LDL-C in the JCADII study. In addition, it could be argued whether a switch from pravastatin to atrovastatin, which seemed to have been often used to further decrease LDL-C in the IT group, was appropriate for the purpose of further risk reduction. In a post-hoc analysis of the Multicenter Study for Aggressive Lipid-lowering Strategy by HMG-CoA Reductase Inhibitors in Patients with Acute Myocardial Infarction (MUSASHI-AMI) trial, ${ }^{11}$ Sakamoto et al revealed that hydrophilic pravastatin $(n=110)$ prevented new $\mathrm{Q}$-wave appearance $(75 \%$ vs. $89 \%$; $\mathrm{P}=0.0056)$ and reduced acute coronary syndrome events (3.6\% vs. $9.9 \%$; $\mathrm{P}=0.0530)$ to a greater extent than lipophilic statins $(\mathrm{n}=131$, including more than 80 patients treated with atorvastatin), despite LDL-C being decreased more potently by lipophilic statins $(-34 \%$ vs. $-19 \%$; $\mathrm{P}=0.0069) .{ }^{12}$ Considering that the reduction in high-sensitivity $\mathrm{C}$-reactive protein levels was comparable between the hydrophilic and lipophilic statins, ${ }^{12}$ it should be emphasized that just changing from pravastatin to atrovastatin might not have been effective in reducing adverse cardiac events in the JCADII study, from the viewpoint of the pleiotropic effect for CAD.

Nonetheless, the results from the JCADII study may shed light on the future direction of intensive management of coronary risk factors in patients with CAD. Although further investigations are needed, the study might suggest that "strict" CT might be superior or at least equivalent to "mild" IT in the treatment of CAD. The "really intensive" therapy could consist of "intensive" considerations of the balance between essential benefits and risks in individuals in this contemporary era of evidence-based medicine.

\section{References}

1. Current status of the background of patients with coronary artery disease in Japan. Circ J 2006; 70: 1256-1262.

2. Kohro T, Yamazaki T, Izumi T, Daida H, Kurabayashi M, Miyauchi $\mathrm{K}$, et al on behalf of the JCADII Investigators. Intensively lowering both low-density lipoprotein cholesterol and blood pressure dose not reduce cardiovascular risk in Japanese coronary artery disease patients. Circ J 2011; 75: 2062-2070.

3. Messerli FH, Panjrath GS. The J-curve between blood pressure and coronary artery disease or essential hypertension: Exactly how essential? J Am Coll Cardiol 2009; 54: 1827-1834.

4. Verdecchia P, Angeli F, Cavallini C, Mazzotta G, Garofoli M, Martire P, et al. The optimal blood pressure target for patients with coronary artery disease. Curr Cardiol Rep 2010; 12: 302-306.

5. Messerli FH, Mancia G, Conti CR, Hewkin AC, Kupfer S, Champion A, et al. Dogma disputed: Can aggressively lowering blood pressure in hypertensive patients with coronary artery disease be dangerous? Ann Intern Med 2006; 144: 884-893.

6. de Lemos JA, Blazing MA, Wiviott SD, Brady WE, White HD, Fox $\mathrm{KA}$, et al. Early intensive vs a delayed conservative simvastatin strategy in patients with acute coronary syndromes: Phase $\mathrm{Z}$ of the A to Z trial. JAMA 2004; 292: $1307-1316$.

7. Cannon CP, Braunwald E, McCabe CH, Rader DJ, Rouleau JL, Belder R, et al. Intensive versus moderate lipid lowering with statins after acute coronary syndromes. N Engl J Med 2004; 350: 14951504.

8. Pedersen TR, Faergeman O, Kastelein JJ, Olsson AG, Tikkanen MJ, Holme I, et al. High-dose atorvastatin vs usual-dose simvastatin for secondary prevention after myocardial infarction: The IDEAL study: A randomized controlled trial. JAMA 2005; 294: 2437-2445.

9. LaRosa JC, Grundy SM, Waters DD, Shear C, Barter P, Fruchart $\mathrm{JC}$, et al. Intensive lipid lowering with atorvastatin in patients with stable coronary disease. N Engl J Med 2005; 352: 1425-1435.

10. Afilalo J, Majdan AA, Eisenberg MJ. Intensive statin therapy in acute coronary syndromes and stable coronary heart disease: A comparative meta-analysis of randomised controlled trials. Heart 2007; 93: $914-921$

11. Sakamoto T, Kojima S, Ogawa H, Shimomura H, Kimura K, Ogata Y, et al; MUSASHI-AMI Investigators. Effects of early statin treatment on symptomatic heart failure and ischemic events after acute myocardial infarction in Japanese. Am J Cardiol 2006; 97: 1165-1171.

12. Sakamoto T, Kojima S, Ogawa H, Shimomura H, Kimura K, Ogata $\mathrm{Y}$, et al. Usefulness of hydrophilic vs lipophilic statins after acute myocardial infarction: Subanalysis of MUSASHI-AMI. Circ J 2007; 71: $1348-1353$. 